\title{
The Rietveld-Schröeder House and the Fifth Element
}

\author{
Tomás García-Salgado ${ }^{1}$ (D)
}

\begin{abstract}
As we know, the aim of architectural design is the materialization of space, a process that we will attempt to comprehend in the mode that the RietveldSchröeder House was built, especially because the house was raised on a privileged plot with three sides free, which is determined to be the fifth element. However, we should ask why wood was used instead of concrete, why the stair is so peculiar, why the first floor has mobile partitions, why the southeast view is so favored, and why the roof is flat in a place where gable roofs are traditionally used. In addition, the question of whether the house design has particular proportions has been raised. These questions are discussed in this article from the architectural point of view based on Rietveld's original drawings of the house.
\end{abstract}

Keywords Rietveld-Schröeder house - Truus Schröder-Schräder · Gerrit Thomas Rietveld · De Stijl · Proportions · Golden ratio · Modern architecture

\section{Introduction}

For something outstanding or special to happen, such as the lining up of the planets, several things must come together at a time. This seems to be the case of the innovative architectural design of the Rietveld-Schröeder house. At the time, this house was not just a new house in town similar to many others. It would be simplistic to give a rundown of the novelty features of the house without understanding where they come from. Architects may wonder how the house program matured in the minds of the architect and the client. Rietveld and Truus

Tomás García-Salgado

josephpalladio@gmail.com

1 Facultad de Arquitectura, Universidad Nacional Autónoma de México, Ciudad Universitaria, Av. Universidad 3000, Delegación Coyoacán, Mexico City 04510, Mexico 
worked together on the program until they came up with the idea of making mobile partitions on the first floor, rather than using brick walls. Furthermore, the stair opening needed to be rectangular shaped on the first floor, to make its layout flexible. None of the architectural features of this house is fortuitous, as we will see.

\section{Truus Schröder}

Soon after World War I came to an end, Dutch society was still in turmoil, but at the same time, they observed an opportunity to rebuild life with a new vision. Families wanted suitable environments to raise their children, whether at school, home, or public spaces. Truus Schröder-Schräder sought the best education she could provide for her children (two girls and a boy). From the beginning, she envisioned a home for the family and social activities. She had a clear idea of how her home should be years before discussing the architectonic program with Rietveld. Still married at the time, her husband agreed to the remodeling of one room of their home as she pleased. This would be her studio, and Gerrit Thomas Rietveld was hired by her husband for this project. Both Truss and Rietveld got along during the remodeling work, placing new furniture, selecting colors for everything, even lowering the ceiling; a little experiment of what would come later. It was the start of a relationship that lasted for a lifetime. Shortly after being pleased with her new room, Truus faced major changes in her life. Her husband died, and she had to decide whether to stay in the same house or start looking for another place to live in. Obtaining an apartment that she could remodel to fit her needs was an option, or perhaps finding a site to build a house. At the time, Utrecht was a small city, and somehow Truus and Rietveld found a small lot at the end of a row of typical brick Dutch houses. Brown says that they chose this site "... because at the time it was the only available site that was accessible to the countryside" (Brown 1958: 37). However, most likely their decision was prompted when they observed that the lot had three sides surrounded by open space, a privileged shape that they could not ignore. Being close to the countryside was a fact, and being small made it amenable to Truus budget. We can speculate what Truss and Rietveld's first thoughts were: for instance, we can place the dining-living room here and place the chambers over there. One side facing over Prins Hendriklaan, the long side toward the countryside, the backside free too, and the fourth side lines up wall-to-wall with the neighboring house. On a lot such as this, as architects know better, there are many options to arrange the spaces because natural light strikes three sides. However, the lot was small (approximately $8 \times 10 \mathrm{~m}$ ), and Truus' program was large. She wanted an open space to reside with the family during the day, but at the same time she wanted the bedrooms to have privacy at night. This was the challenge to tackle. Otherwise, if Truss's budget had allowed her to buy a larger lot, then the spaces would have been planned separately for each use. 


\section{The Fifth Element}

The day that Truss and Rietveld sat down at the table to discuss how to start goes back to an unexpected chain of events. It started with Truss's ideas on infant education, strongly supported by her sister An, which sowed in her an early vision of what her home should be like. Then, her first encounter with Rietveld to design her studio led her to be acquainted with the wide vision of De Stijl art. She became a widow and started looking for a new home in Utrecht, hoping to move to Amsterdam someday. For the time being, Rietveld was already part of De Stijl movement; his red and blue chair fulfilled the neoplasticism ideals, and he was ready to take on architecture. Finally, the fifth element adds up to a chain; it was a small lot at the very limit of the city waiting for the architect and client to raise a house on it. Just think, what if she had no special ideas on education, what if she never met Rietveld, what if she became a widow at a very advanced age, what if she never related to De Stijl, and what if the fifth element had had only two free sides; would the Rietveld-Schöeder house be as we know it? I guess not. As a matter of fact, this correlation of events explains the very nature of the house in all of its aspects.

\section{The House Design}

Let us see now the architectural design of the Rietveld-Schröeder house, built in 1924 in Utrecht, the Netherlands (Figs. 1 and 2). ${ }^{1}$

Looking at the ground floor and the first floor highlights the atypical design of the staircase, which is divided into two sections, makes us wonder why it was done this way. Analyzing carefully the layout of the first floor, it is obvious that there was not enough room to place the stair ramp completely; the same situation applied to the ground floor. The staircase shape, on the first floor, had to be rectangular and exactly in the position as it is; otherwise, the use of the floor space would not be flexible because it depends on the stair landing. There is no other option to have a hallway of minimum circulation that connects all of the rooms. To prove this assertion, it suffices to rotate the position of the current hallway $90^{\circ}$ to see how the layout of the first floor turns out to be difficult to subdivide. This explains why the staircase, from the ground floor to the first floor, combines a short straight ramp with an intermediate landing, which then rotates $90^{\circ}$ in the shape of a fan-ramp, resulting in a passage that is variable height between both ramps of low height $(\approx 1.94 \mathrm{~m}$ ). After climbing the four steps of the short ramp, there is a wall with the telephone and the fuse box, a small seat with a leather backing band, and storage space under the landing. The staircase resembles another piece of furniture in the house. It is true that the central position of the staircase (in the house) makes the distribution of both floors efficient, but it is also true that the staircase is not easy to climb or descend

\footnotetext{
1 The architectural drawings of the ground floor and first floor show in detail the distribution of the house. These drawings, with names written in Dutch, look like the 1920s type and match perfectly with the original Rietveld drawing (discussed in the next subhead). Most likely these drawings were used to set the layout on the ground.
} 


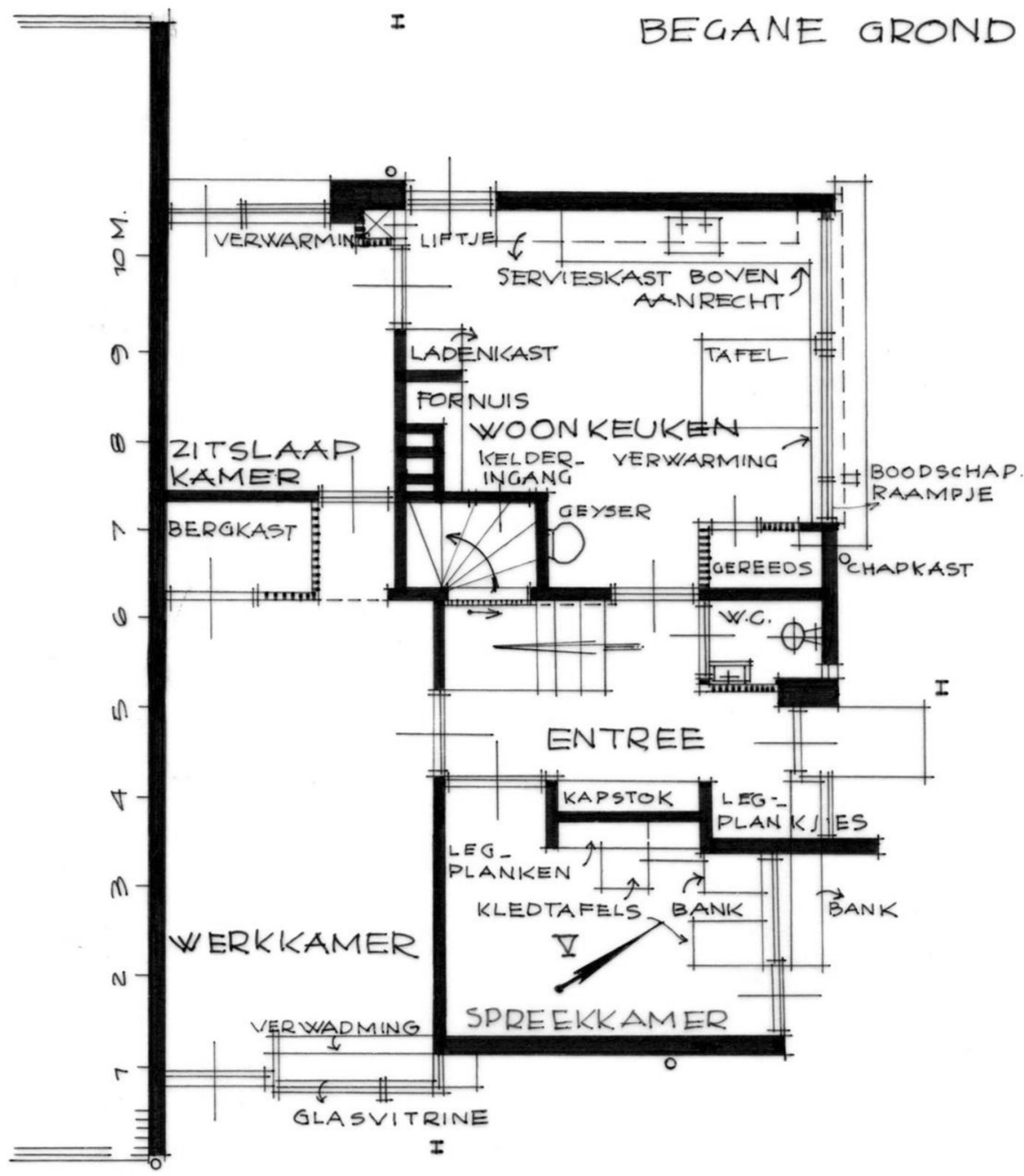

Fig. 1 Ground floor. This drawing was our main source to retrieve the dimensions and proportions of the house. Legend: Ground floor (Begane Grond), Heating (Verwarmin), Dumbwaiter (Liftje), Tableware Cabinet (Servieskast), Work Place (Boven Aanrecht), Table (Tafel), Loading Cabinet (Ladenkast), Stove (Fornius), Living-Kitchen (Woonkeuken), Bedsit Room (Zitslaadkamer), Basement Entrance (Kelderingang), Message Window (Boodschap Raampje), Storage Cabinet (Bergkast), Tool (Gereeds), Interphone-like (Chapkast), Water Heater (Geyser), Entrance (Entrée), Coat (Kapstok), Boards (Legplankjes), Shelves (Legplanken), Bank (Bank), Extendable Table (Kledtafels), Speaking Room (Spreekkamer),Work Room (Werkkamer), Glass Display Case (Glasvitrine). Image: by the author after Rietveld's original drawing

quickly due to its narrow design. This could have been the true reason why the house did not comply with the fire regulations at that time and why the first floor has to be called the 'attic'.

Although the Truus room was the smallest in the house, it expands visually to the balcony and to the living-dining room by sliding the partition panels. The same 


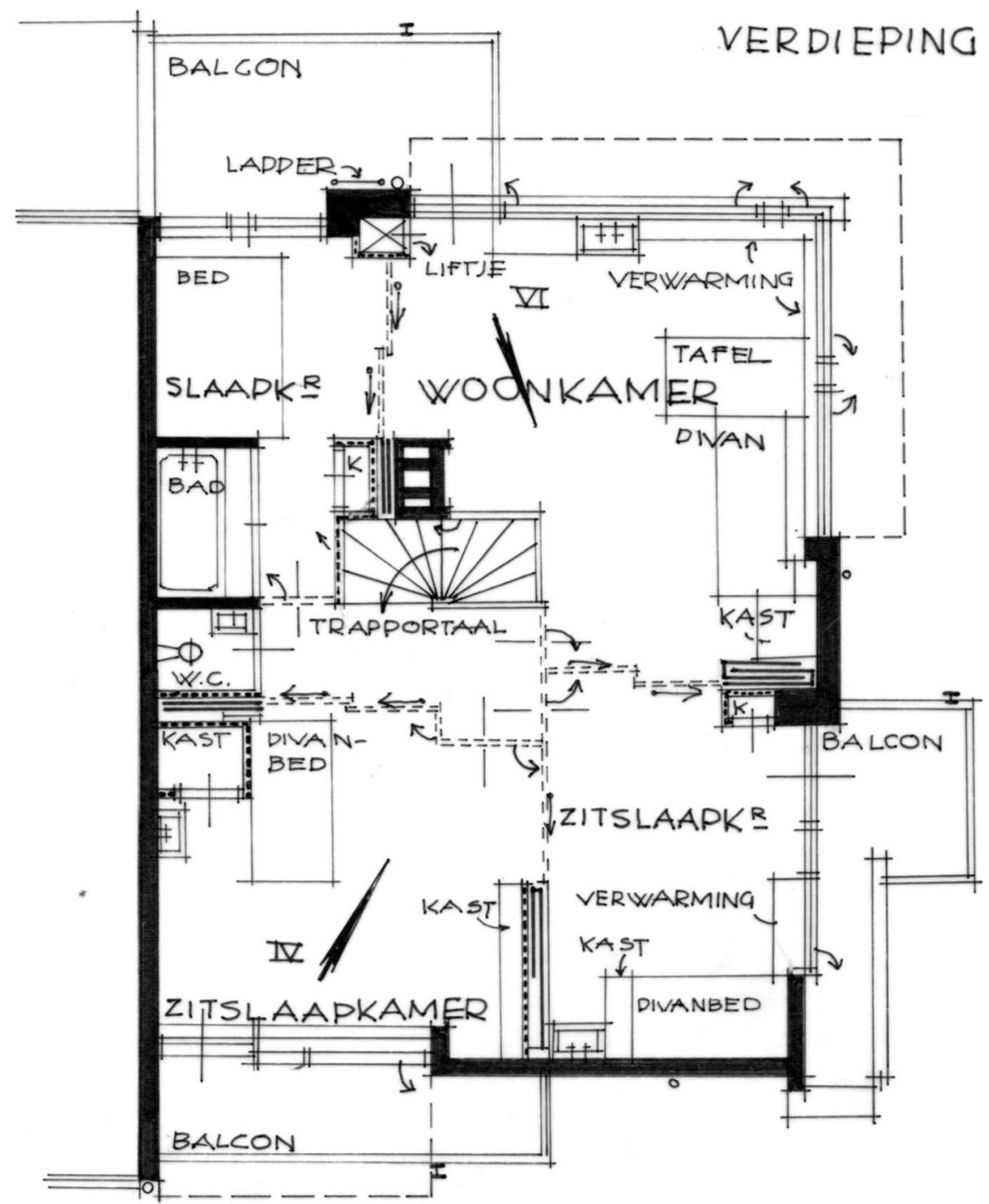

Fig. 2 First floor. Legend: Balcony (Balcon), Ladder (Ladder), Bed (Bed), Bedroom (Slaapkamer), Living Room (Woonkamer), Divan (Divan), Bath (Bad), Stair Portal (Trapportaal), Closet (Kast), Sofa (Divanbed). Image: by the author, after Rietveld's original drawing

spatial integration can be done for the boy's room by sliding the partition panels next to the dining-living room. In addition, the girls' room can integrate with the hallway, and with the living room if the boy's room partitions are open. The first floor is as flexible as the users wanted to adapt it, only by choosing which panels they should move. Basically, the room is a large room for daylight family activities that transforms into individual small rooms to rest in at night. However, the big question is whether the fire regulations urged Rietveld to consider partition panels. 
In the first floor blueprint (Fig. 2), at the perimeter of the staircase, the system of sliding and revolving windows used to isolate its access to the dining-living room is indicated. More noticeable are the mobile panels, drawn one by one, indicating the sliding and revolving movements with arrows. In my opinion, the mobile panels seem to replace the brick walls that were previously drawn in the traditional manner. This conjecture is based on the layout of the doors facing the hallway; two of them are contiguous and another is at an angle that is commonly used to confine bedrooms with brick walls. What other explanation could be given when Truus ask to Rietveld: "Can those walls go too?" To which he replies: "With pleasure, away with those walls!" (Frietman 1998: 76). This suggests that the initial idea was to divide the bedrooms with brick walls; otherwise, she would have not said can those walls go too. I believe what Truss meant by 'go' was 'move', to have an open space during the daylight. Therefore, we draw the first floor with walls, instead of mobile panels, to have an idea of how it would look (Fig. 3). We find that the theoretical walls make sense for a traditional layout of a three-bedroom floor, which probably was the idea at the first stage of design. However, the idea of mobile panels to remove the solid walls and thus leave the use of the space flexible (according to Truus's lifestyle) was an original invention of Rietveld, which for the most part is the paramount feature of the house.

Rietveld must have enjoyed solving the sliding and revolving panels as a puzzle to fulfill Truus's request, which, in the end, changed the ordinary design of a house into an extraordinary house. Rietveld, as a true craftsman, more in the logic of a cabinetmaker than an architect, thought of making the movable panels as if they were a kind of furniture. The new trend in furniture design at the time was to make them lightweight using straight forms, so the partition panels continued this trend. However, all of these were just the beginning. It follows now how to make it come true.

\section{The Blueprint}

The drawing of the house that we consulted "is the original drawing after the changes Rietveld made"2 (Fig. 4). It is a large sheet that contains three elevations, three sections, the structural plans of the ground floor, first floor, and the roof, with all of the names written in Dutch.

The location schema of the house at the sheet foot (standard information required for licensed blueprints) suggest that it is the sheet that was used to get the construction permission. Of all of the drawings within the large sheet (referred to as the blueprint from here on), it calls to attention the implant of the roof structure drawing, noticeable by the trace of a gummed frame. This could be a rectification of the roof joists layout, which probably was oriented as on the first floor. Additionally,

\footnotetext{
2 A confirmation I received by e-mail (March 27, 2017) from Natalie Dubois, curator design and applied arts of the Centraal Museum in Utrecht, the Netherlands. This drawing is on the Internet, in the Rietveld Schröederarchief, Central Museum, web page: Date of creation: 1924//Technique: pencil and ink on transparent//size: $69.3 \mathrm{~cm} \times 49.5 \mathrm{~cm} / /$ Source: [004 A 001] Rietveld Schröederarchief, Central Museum; see also https://www.pinterest.com/justmyair/rietveld-schröderhuis/.
} 


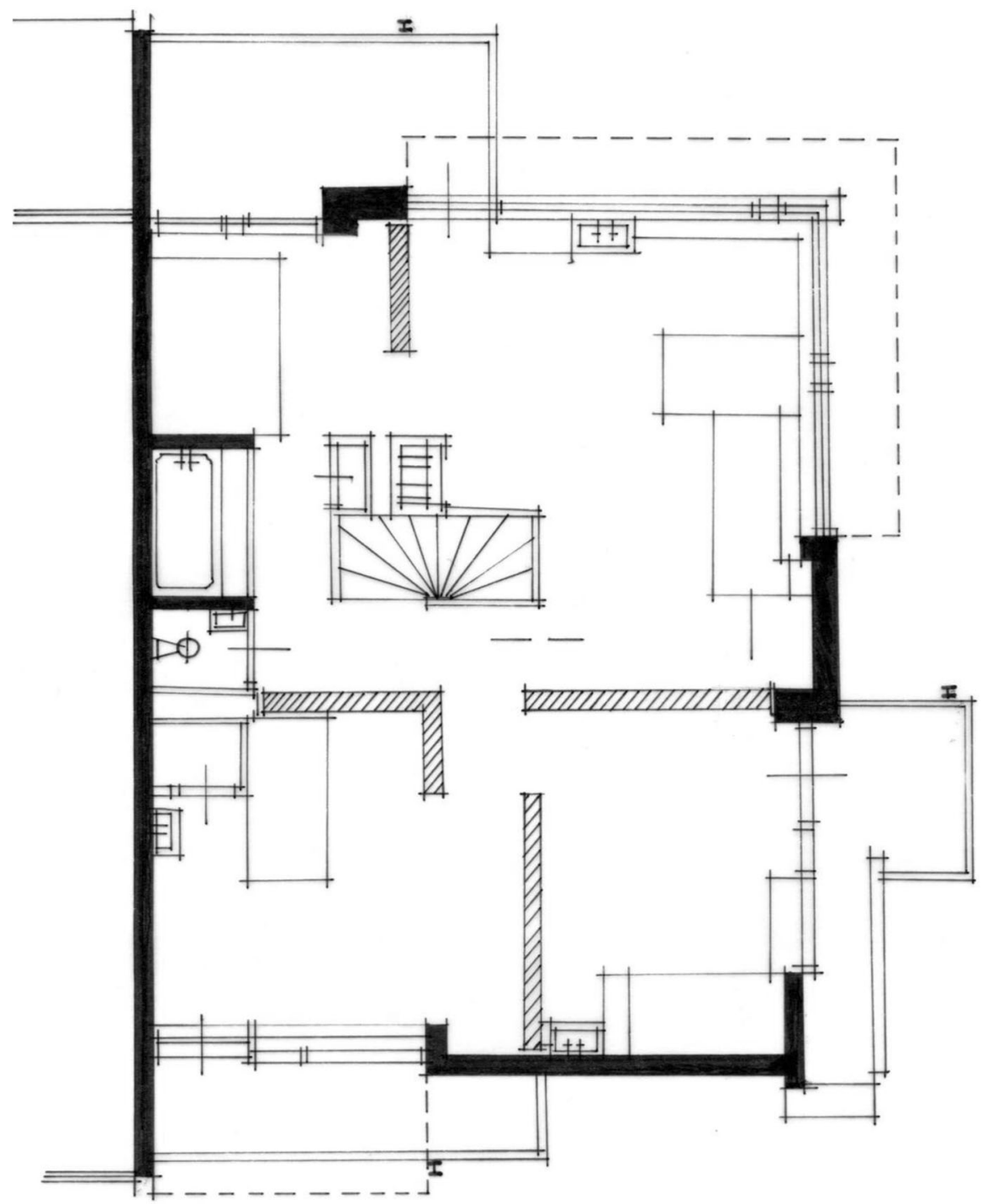

Fig. 3 Hypothetical plan of the first floor with walls instead of mobile partitions (author's drawing). Here, we see a traditional layout of a three-bedroom floor, which probably was the idea at the first stage of design. What other explanation could be given when Truus asked Rietveld: "Can those walls go too?"

we can notice in the blueprint that the entire first floor was labeled the attic (zolder) to comply with the building fire regulations. This makes sense with Truss's request ("can those walls go too?"), possibly because she wanted to prevent the authorities from arriving and finding no attic at all. Years later, when the house was restored (1970s), a second blueprint was elaborated, which looks almost the same as Fig. 4, with minimal additions and changes. For instance, the mobile partitions are clearly indicated, and the first floor is no longer called the attic. 

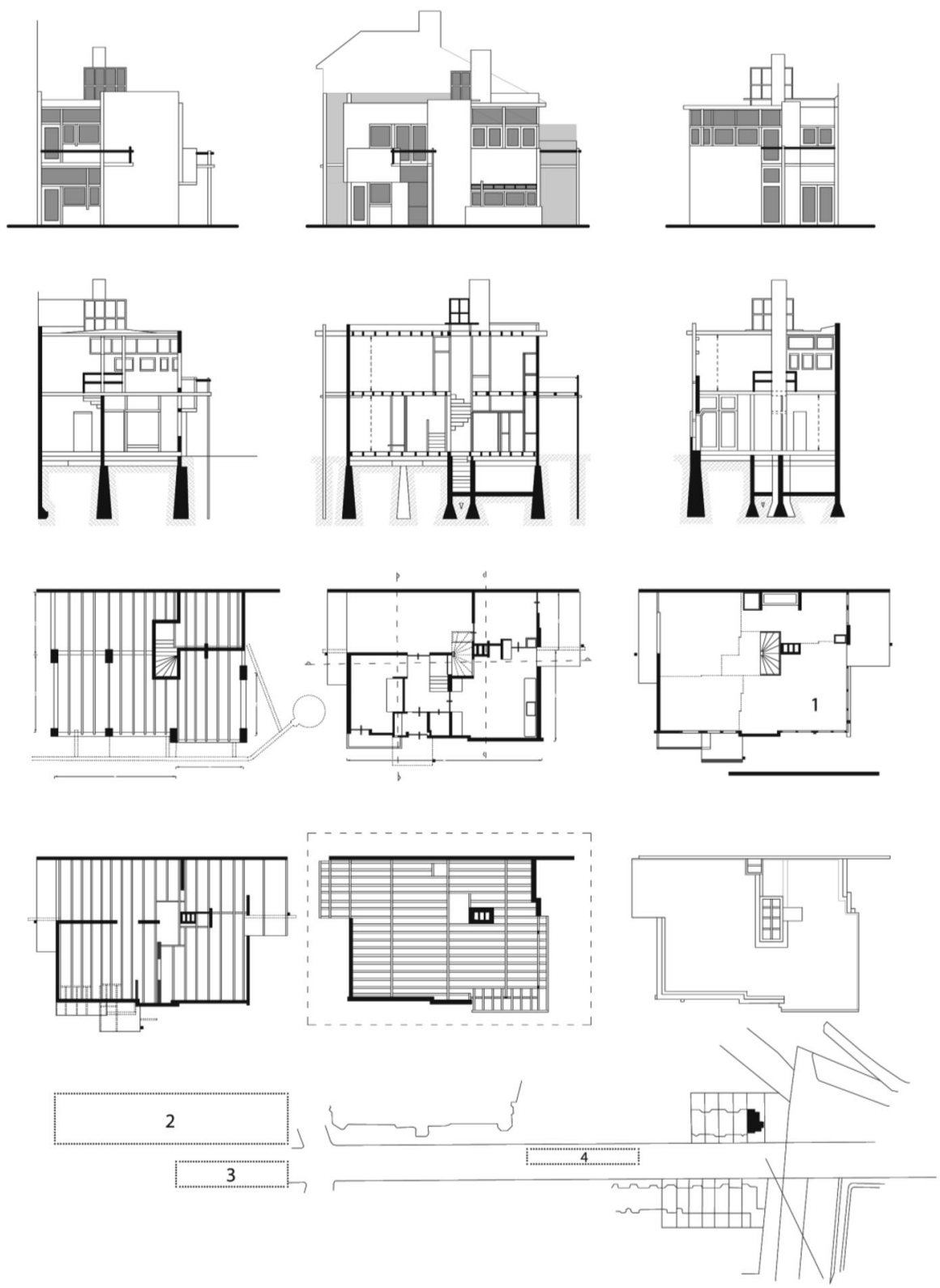

Fig. 4 Facsimile drawing of Rietveld's original blueprint, at the Centraal Museum in Utrecht, the Netherlands. All figures from left to right. First row: southwest façade, southeast façade, northeast façade. Second row: cross-sections. Third row: structural plan at ground level, ground plan, (1) first floor or the attic (zolder). Fourth row: structural plan of first floor, structural plan of the roof (dashed lines indicates the inserted drawing area), plan of the roof. Legend: (2) Plan for house Prince Hendrik L (Plan voor Woonhuis Prins Hendrik L) Utrecht kadaster 3230 (Utrecht land register 3230). (3) Rietveld's signature. (4) Situatie (site) Prins Hendriklaan 50. Image: the author and Brenda D. Macías 
In the blueprint, the floor's structure and the roof are indicated in wood, except the balconies that are in concrete (including the parapets). If the floors had been poured in concrete, then the balconies would have been cantilevers. Most likely Rietveld was not familiar with concrete and its method of employment at the time, or perhaps it was not affordable for a small house; or the fact that the roof spans over $7.5 \mathrm{~m}$ was the reason to make it with wood instead of concrete. To support the balconies, Rietveld used an I-column and an I-beam strategically placed (see blueprint). ${ }^{3}$ The vertical steel columns and the beams joint tangentially, similar to the arm supports, stretchers, and mid rail of the Red and Blue chair (known first as the Slat chair, 1919). This system of joining is present in most of the constructive elements of the house. The facades are highlighted by the juxtaposition of columns and beams, emphasizing the partitions of the windows with horizontal and vertical steel bars, all painted with the colors of the De Stijl palette. This treatment, handling each element of the facade separately, is what labels the house with the signature of De Stijl. The interior looks convincingly similar to a Mondrian painting, but in 3D (Fig. 5), even though Rietveld and Mondrian never met in person (Bois 1987: 105).

\section{The Corner Window and the Overhang}

The way in which the corner window of the dining room opens is interesting. The two windows panes that form the corner, one larger than the other, have their jambs in such position that once they are opened, the corner is empty because they do not close at a fixed mullion. Because each window is adjoined to an I-column, and in turn, the I-columns lie on the walls that form the corner, there was no need to place a column at the corner. Therefore, we should examine the structural plan of the house roof. It is clear that the beams were arranged longitudinally to facilitate the draining of rainwater, clearly to the short sides of the roof. Therefore, to support the corner overhang and prevent it from bending down, it was necessary to add seven short transversal joists. Therefore, the logical points to place the I-columns that support the overhang are (a) at the intersection of a main transverse beam with the beam carrying the short joists and (b) at the intersection of the longitudinal beam (which also carries the short joists) with the facade transversal beam. This is why despite placing both I-columns along the corner-window perimeter, their axes do not intersect at the corner. This fact leads us to speculate that the invisible corner was not preconceived; rather, it was derived from the structural design of the roof beams. In addition, the I-columns do not reach the ground; they are embedded at mid-height of the walls. However, what if the true motivation of the corner window was something else than making it invisible? To obtain an answer, we bring Robert van't Hoff into the scene.

Van't Hoff commissioned Rietveld to copy some furniture pieces of Frank Lloyd Wright. Most likely, Robert lent Frank Lloyd Wright's Wasmuth Portfolio (Wright 1910) to Rietveld or gave him some photographs that he took of the houses and

\footnotetext{
3 In Rietveld's archive, there is a constructive drawing of the first floor beams layout that includes the detail of the concrete reinforcement for the balconies' floor and one of the parapets.
} 


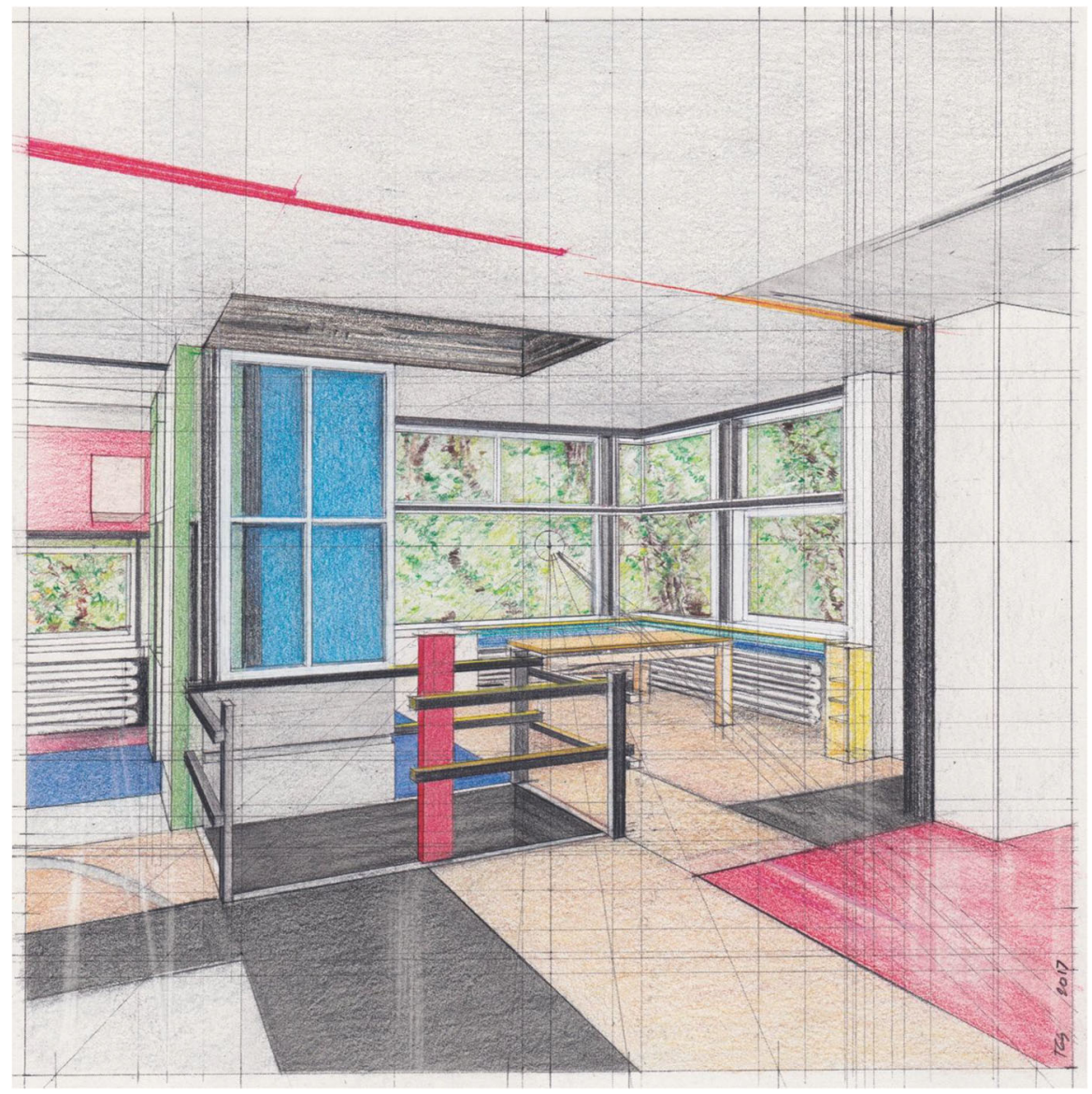

Fig. 5 Drawing in modular perspective of the interior of the house based on Rietveld's blueprints. The vantage point, here reproduced, is the same as in Rietveld's perspective drawing. The observer sightline runs almost on a golden line, whose points of interest are the following: a the corner of the balcony handrail behind the observer, and $\mathbf{b}$ near the corner post of the handrail in view (see Fig. 6). Image: the author and Brenda D. Macías

furniture on site. Years before, Robert went to the USA to see in person Lloyd Wright's architecture, in which he found a source of inspiration. Some of the houses that he designed clearly show Lloyd Wright's influence. ${ }^{4}$ Anyone who sees Lloyd Wright houses in site (or even in books), cannot overlook the pronounced cantilevers casting strong shadows on their facades. Therefore, Rietveld most likely did not overlook this part. In a way, the flat roof with pronounced overhangs of Van't Hoff's Villa Henny may have had some influence on the Schröerder house as well. To support the overhang of the corner window, Rietveld did not use the I-beam and post system as he did for the balconies. I think that he wanted to make the

\footnotetext{
${ }^{4}$ See, for instance, Villa Henny (1915-1919), and Villa Verloop (1915-1916), both in Huis ter Heide, Utrecht.
} 
overhang resemble a true cantilever, in Lloyd Wright style. Additionally, the lintel along the kitchen window, forming a ribbon window, undeniably is the way that Lloyd Wright used to stress the windows. These similarities of style lead me to question, why did Rietveld make the roof flat (like in Van't Hoff's Villa Henny) in a place where the houses' roofs are predominantly gable roofs? I guess that the main problem of Rietveld's roof is keeping it waterproof. This is not a problem for Villa Henny's concrete reinforced roof.

It would be interesting to have the complete anatomy of the house. It suffices to wonder, for instance, about the kind of wood employed to build the floor and the roof, and the type of assembly details. How the floorboards were placed. How the system of the sliding panels was built. How the smooth surface of the dining-living room ceiling was done. Whether the kitchen window lintel is a steel girder with wire mesh. The access to the food warehouse from the kitchen. The kind of reinforcement that was used for the balconies slabs. Even about minor elements such as the lighting and the intercom; and how the dumbwaiter connecting the dining-living room to the kitchen works. However, what we know for certain is that the house was made to a great extent of wood, exactly the material that Rietveld was familiar with. I dare to think that Rietveld shaped the house as if it were, in a way, a big piece of furniture. He took care of every constructive piece of the house, successfully.

\section{On the Proportions of the House}

There is no a clue that Rietveld used any kind of geometric system for the design of the house. As Bertus Mulder says, "He [Rietveld] did not design abstract systems, but concrete shapes of wood, glass, stone or plastics" (Mulder 2010: 57). Therefore, we focus on Rietveld's own ideas about architecture, as he stated in his article Inzicht (Insight): "De werkelijkheid, die de architectuur scheppen kan is de ruimte" (The reality that the architecture can create is the space) (Rietveld 1928: 90). This idea faithfully portrays the basic composition of the house; as Mulder put it: "Rietveld created that space by positioning demarcations: four vertical panels and two horizontal plates" (Mulder 2010: 57). For clarity, the "panels" are actually walls, and the "plates" are the floors (the first floor and the roof). From the basic volume of the house, as the initial formal grammar, the windows, doors, and sliding partitions were derived; that is, forms repeats everywhere, varying only in size and material.

To determine whether the Schröder-Rietveld House has identifiable proportions, the only reliable source that we have is the Rietveld archive at the Central Museum in Utrecht (The Netherlands). The archive is quite extensive. The material is not yet classified, so one must sort it by subject while guessing most of the dates. We managed to look through the archive, searching mainly for drawings. We found many preliminary drawings and several detailed blueprints as well, among which there is one for the restoration of the house. In addition, there are photos of the house already finished, a few under construction, some more of the house's model, and diverse documents. In regards to the drawings, there are plans, facades, sections, 
perspectives, details, and a few sketches of the land lot with the house. The care that Rietveld took to prepare detailed drawings of the windows and doors (at larger scale) is remarkable, including a plan of the stair next to the access indicating the sliding doors, the I-columns of the living-room in plan and elevation, the kitchen window, and other details. The detailed drawings reveal how each element of the house ought to be placed and joint with the others, thus creating different planes of composition. This way, the craftsman would understand how each element is viewed from the outside and the inside at the same time. In the archive, there are several perspective views of the interior. We choose one of them, and taking a similar vantage point on Rietveld's plan of the first floor, we draw it in Modular Perspective $^{5}$ (see Fig. 5). Later, when we were analyzing the proportions of this floor, we realized that the observer's sightline almost coincides with a golden line.

Other sketches contain measurements that appear to have been taken at the site, not of the type commonly used to build. Some of these drawings were made freehand, though it is difficult to verify general measurements due to its low resolution. Another group of drawings, in the archive, with captions written in English, suggests that they were used for publications in this language. Once we classified the drawings in groups, we attempted to discern which of them most likely were made by Rietveld. In sum, no major differences in the blueprints were found; that is, the stair always appears around the same location, there were minimal variations in the walls' position, and there seem to have always been three balconies (never two or four). In other words, it looks that there was never a plan B, not in the archive at least.

Among the archive drawings, one caught our attention. This drawing is quite similar to that of Fig. 4 (facsimile blueprint of Rietveld's original blueprint), except for the fact that the caption at its foot reads: "plan voor restauratie van het Schröder-Rietveld huis" (plan for restoration of the Schröder-Rietveld house). Next, to this caption, the schematic urban location was updated to show the highway and underpass built in the 1960s that passes nearby the house. Since the blueprint is not dated, we do not know whether it was elaborated before or after the underpass was built. What we know is that the restoration of the house was initiated in $1974 .^{6}$ In any case, the blueprint in question (from here on called "the restoration blueprint") was drawn decades after the one shown in Fig. 4; however, both look almost identical. Curiously, the one constructive detail that the restoration blueprint has reads: "muurbe-eindiging boven het dak" (wall end above the roof), which clearly indicates that the waterproofing of the roof was a major problem. A comparative examination of both blueprints shows minimal differences regarding the walls' disposition of the ground floor. In turn, the first floor is no longer called attic because the rooms are named (not readable due to low resolution), and the sliding partitions are clearly indicated. Another feature of the restoration blueprint is the indication of some partial and total measures, of which the length of the back wall reads $13 \mathrm{~m}$. The length of this wall, as deduced from the graphic scale of the

\footnotetext{
5 About modular perspective see (García-Salgado 2016).

6 (Mulder 2010: 45-47). At the request of Truus Schröder, Bertus Mulder was put in charge of the restoration.
} 
drawing (see Fig. 1), is approximately $12.7 \mathrm{~m}$, though it may be slightly longer if both their ends are aligned with the wall of the neighboring house. In addition, the resemblance between the blueprint and the restoration blueprint is remarkable; in both, Rietveld's signature is in the same location, as if it were copied.

The plans and facades, essential for our search of proportions, seems to be repeated with little changes from one another. These drawings suggest that Rietveld was studying the composition of the elements more than once; however, none of them shows stroke lines to set out proportions. At this point, it was clear that all of the proportions that we might find should be based on the drawings themselves, not on the house as it was built. Architects are aware that in practice the blueprints are frequently modified during the construction process. Thereby, we choose to analyze the drawings that depict the house consistently and that we believe are the original ones. We knew beforehand that proportions as a system of design were not intended by Rietveld because "he did not design abstract systems, but concrete shapes...".

Therefore, where to start? A simple procedure might be by drawing lines from any corner of the house to see what crosses in its way. However, the relations established this way would be merely coincidental unless the angle of the tracing lines was constant. The idea of carrying lines across the corners of the windows, as well of the façade and balconies, was promising. We cannot overlook the vertical and horizontal elements of the windows and balconies as part of the neoplastic language of the house. Hence, we started by analyzing how the house was placed on the land lot (the fifth element). In the process of laying out the house within the land lot, something unexpected came up. According to Rietveld drawings, ${ }^{7}$ the length of the long size of the house can be estimated at $\approx 13.00 \mathrm{~m}$, and the short side (up to the exterior wall of the kitchen) $\approx 8.00 \mathrm{~m}$. The ratio of the sides turned out to be nearly the golden ratio because we have $\approx 13.00 \div 8.00=1.6000 \approx 1.6180$. This is a fact that we could not ignore, which raises the question at the same time of whether such dimensions were set out on purpose or if they were the result of the program layout. In this regard, we have to consider two facts. First, the lot size is approximately $25.15 \times 10.60 \mathrm{~m}$, and second, to place the house in the lot, the urban restrictions required alignment with the houses on Prins Hendrik Street, as well on the back with the other houses' garden. For the most part, this explains why the house sides ended up measuring $\approx 13.00 \times 8.00 \mathrm{~m}$.

Now, to carry out the analysis of proportions of the house, we have to introduce here the concept of a golden line, which is defined as follows. A golden line is the line joining two opposite corners of a given golden rectangle, whatever their corners orientation may be in space. In turn, any corner of a golden rectangle will be called a point of interest to identify real elements of the house. Therefore, a golden line in principle can have four orientations on a plane by symmetry: two in vertical reflection and two in horizontal reflection. In practice, when a golden line freely slides over a floor or elevation until it coincides with two points of interest, it is said that it forms a golden rectangle. In our case study, we noticed that all of the golden rectangles overlapped one another (Fig. 6) because two points of interest do

\footnotetext{
7 The measures of the house are deduced from the graphic scale marked out along the back-wall (see Fig. 1), and in some other Rietveld's drawings. Thereby, these values are approximate.
} 


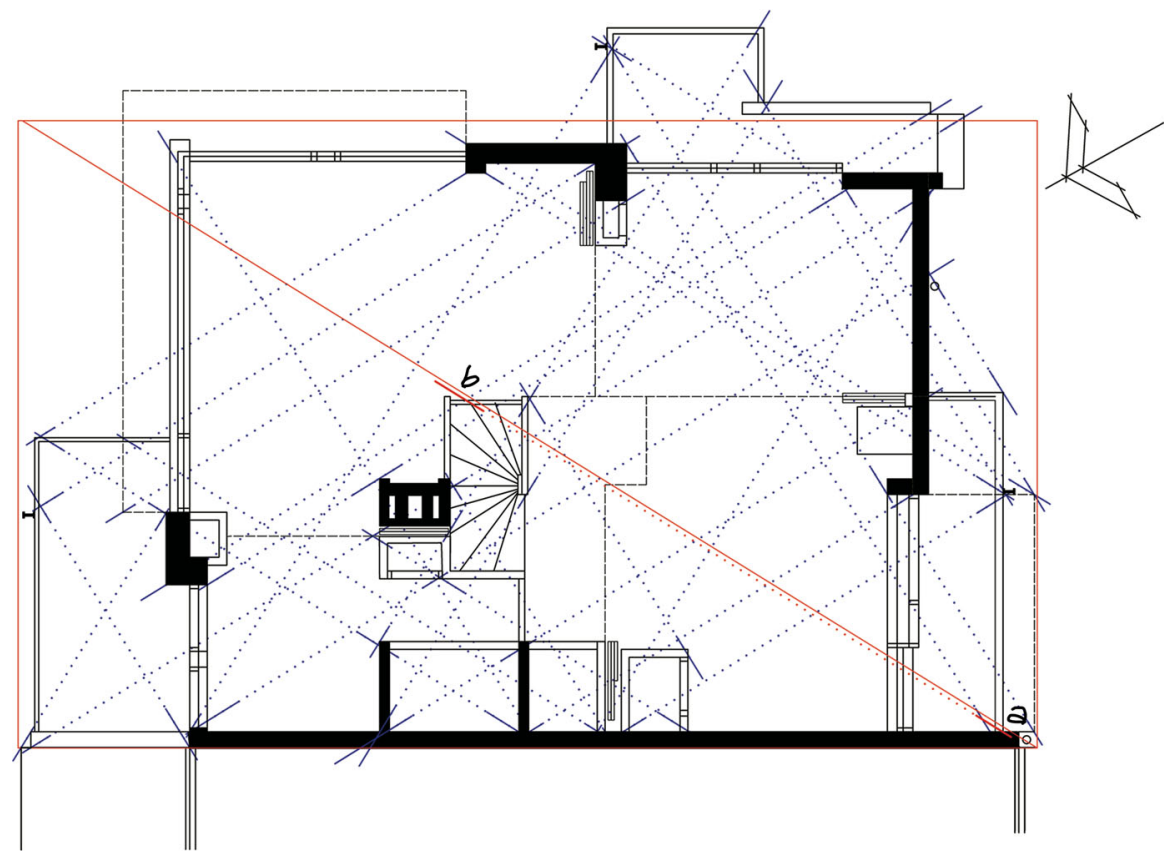

Fig. 6 Golden lines all over the first floor based on Rietveld's original drawing. The boundary of the house is marked out by a thin line (in red). This is the main golden rectangle, with its diagonal from corner to corner. Image: the author and Brenda D. Macías

not necessarily belong to the same element of the house. The fundamental idea of using points of interest is to joint any of the elements of the house as long as they pertain to a golden line. This is why golden lines cannot be arranged in sets or conform to any kind of a system; they rather have to be interpreted independently of one another, as an observer usually does when seeing a real space; for example, when the observer places himself on a line that joins a corner room and a distant balcony corner to see how they relate.

Under this criterion and knowing that the house is approximately shaped by a golden rectangle, my assistant, Brenda D. Macías, and I found a considerable number of golden lines on the first floor and the facades, while on the ground floor, we found just a few. To make the job easy, we needed a tool to slide golden lines anywhere on Rietveld's blueprints. This tool is quite simple, being a transparent $45^{\circ}$ triangular ruler over which the four positions of the golden lines are drawn from the center of its base. This way, we were able to handle the four positions of golden lines at once. This improvised tool helped us quickly find elements related to the golden ratio in both plan and elevation. As we will see, there are many golden ratio relations all over the house, especially on the first floor and the façades. However, because we did not find visible traces of proportions in Rietveld's drawings, it was imperative to put forward a hypothesis to validate our procedure. 
Hypothesis If the house sides are approximately in golden ratio, then some of their components might be in the same proportion, whether they are next to each other or isolated.

\section{Proportions in Golden Lines}

Once we started the analysis of the first floor plan, it was evident that many golden lines might be found due to its open disposition. Instead, on the ground floor, just a few golden lines come out (which the reader may deduce in Fig. 4). In Fig. 6, we can see many golden lines all over the first floor, running either from the corners wall-to-wall, from the walls to the balconies, or from the walls to the I-beam columns. In addition, a golden line runs from a corner wall to the corner of the roof overhang. These lines are indicated as dotted lines in the given four directions for the golden lines. Evidently, the open space of the first floor makes it possible to outline approximately 30 golden lines. The notorious presence of these lines raises another question: how are their proportions perceived in the actual space? We assume that standing in the middle of a golden line, and looking towards the points to which it relates, would have produced a sense of harmony. In this sense, Rietveld's interior perspectives can tell us what his vision of harmony was and what art expression he was after in architecture.

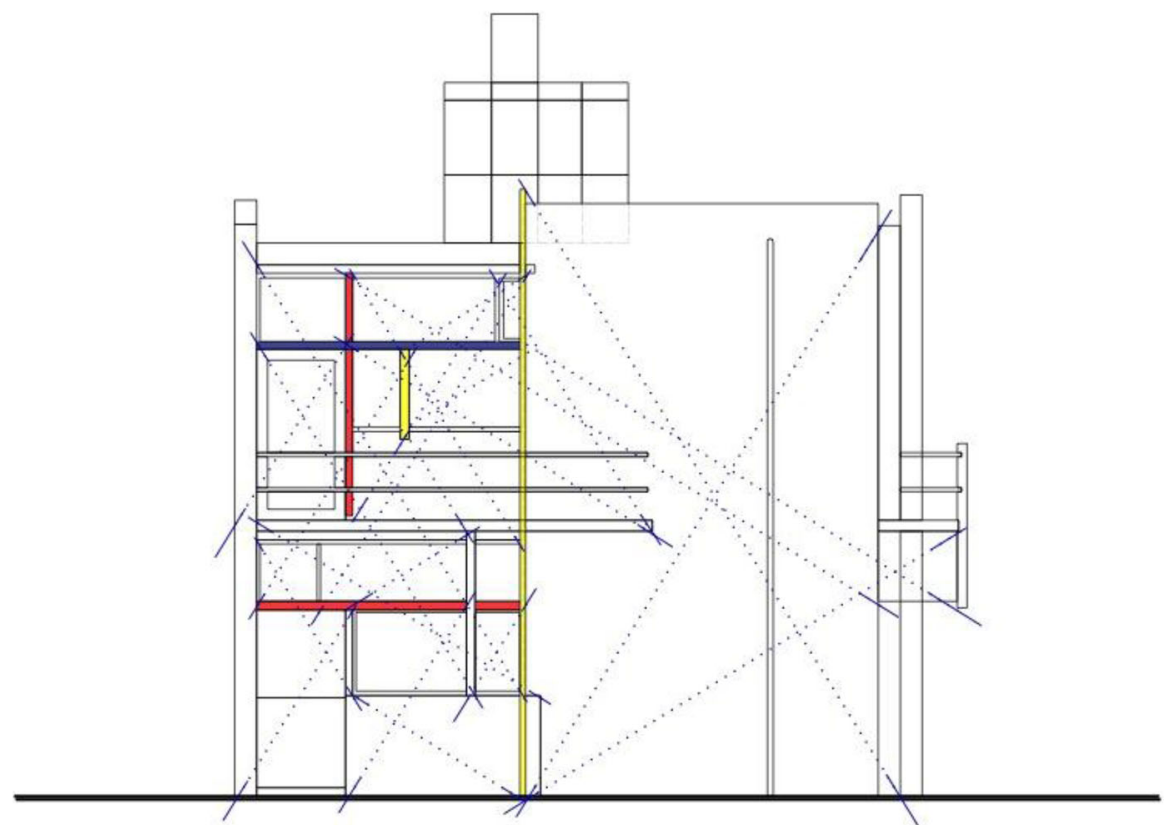

Fig. 7 Golden lines on the southwest facade, based on Rietveld's original drawing. The golden lines flow freely throughout the façade, joining points of interest. Image: the author and Brenda D. Macías 
Next, we prepared facsimile drawings based on Rietveld's façades to carry out their analysis. While drawing the Southwest facade (Fig. 7), which in a way is similar to recreating it, we realized that the shifted planes of the windows' vertical and horizontal elements had been carefully studied. The idea of having the elements joined by their sides without intersecting clearly was to ensure their 3D visual reading, a feature that Mondrian's 2D paintings do not have. During this period, the Rietveld-Schröeder house has become the paramount architectural example of De Stijl. As can be seen in Fig. 7, there are several golden lines in the four orientations; among them, those that entirely encompass the blind wall are remarkable. Additionally, notice how the yellow bar, on the first floor window, has a double golden line; one from the bottom of the red bar up to the upper small window, and the other one from the top of the red bar toward the yellow I-beam column. We came up short when trying to express verbally what perception of harmony really means. However, when one draws line-by-line a facade such as this, one perceives how their correlations, form, and dimensions are put in such a way that if a line were moved, it would break its geometrical balance.

The Northeast facade (Fig. 8), which is my favorite, also has 19 golden lines. These lines make sense to a great extent because the walls, similar to the window bars, are in shifted planes. See, for example, the left golden-line that rises from the kitchen lower wall up to the upper window. If the kitchen lower wall were not in a shifted plane, then such a line would not make sense. In turn, the southeast facade looks to be in perfect balance (Fig. 9). Here, there are three elements that gives the first floor the appearance of being shortened in height. The parapet of the balcony, the entrance door, and kitchen window emphasize this effect. This is not a whim of form; there are some structural reasons, such as occluding the beam that supports the parapet, lowering the high of the entrance door, and confining the I-column of

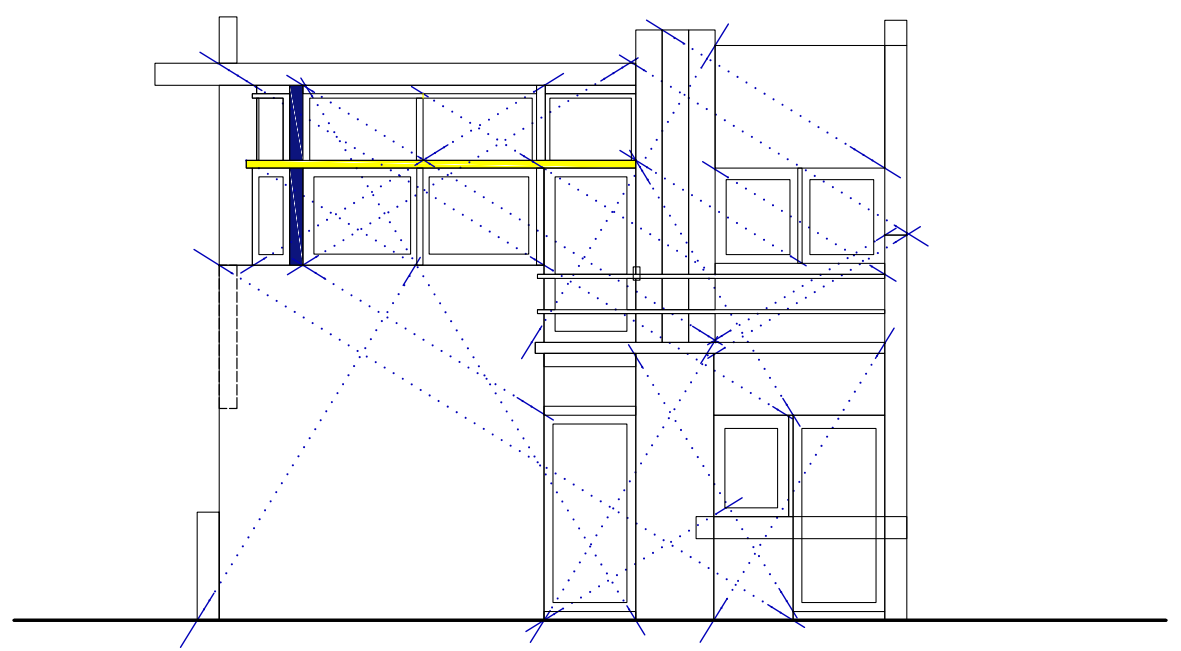

Fig. 8 Golden lines on the northeast facade, based on Rietveld's original drawing. We did take Rietveld's architectural idea of working with overlapped planes when drawing golden lines. Thus, a golden line can shift planes to find on its way points of interest. Image: the author and Brenda D. Macías 


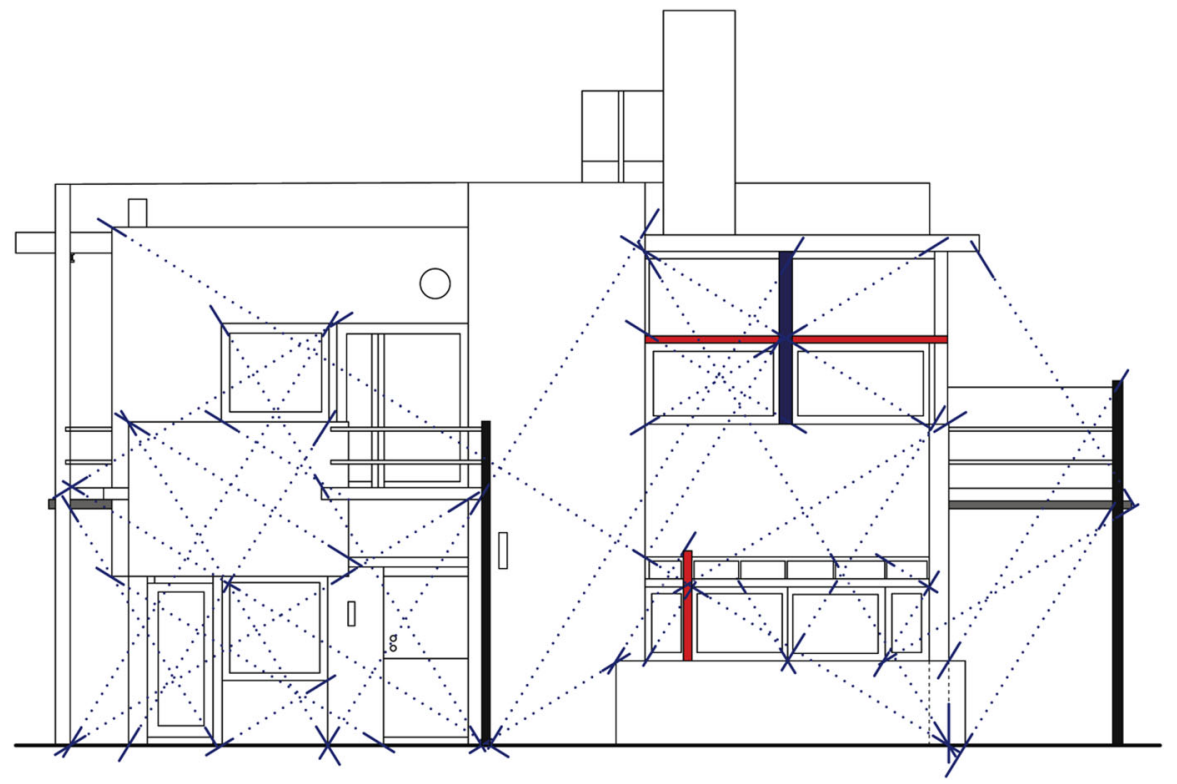

Fig. 9 Golden lines on the southeast facade, based on Rietveld's original drawing. Notice how the golden line that runs from the upper left corner to the lower wall of the kitchen reaches the ground where the lateral perpendicular wall also reaches it. In the house, most elements overlap one another, walls included. Image: the author and Brenda D. Macías

the living room. In this way, the facade elements can be read independently, while at the same time they give a sense of the whole. As we know, human sight perceives in perspective, not in orthogonal projections; however, human sight has the ability to somehow preserve the actual dimensions of the objects viewed. Thereby, the appreciation of the golden lines does not change either in the drawings or in front of the actual house.

Finally, we prepared a facsimile drawing of Rietveld's detail for the kitchen window (Fig. 10). We did this to test the accuracy in deducing proportions between large drawings and small drawings, which was not significant; as can be seen, Fig. 10 has the same golden lines as Fig. 9 has. If we take a close look at Fig. 10, we can identify 6 shifted vertical planes. What would occur if a golden line, instead of running on a single plane, also ran on the shifted planes? Could this be more interesting than the golden lines shown here? Just think, what if a golden line that seems not to make sense on a 2D plane actually does make sense when it shifts to a second or a third plane. The door is open for new insights.

\section{Conclusions}

If the first floor had not been an open space, then it would have not made sense to speak of golden lines in this article. It suffices to say that on the ground floor, we observed few golden lines. Instead, on the façades, as they were analyzed 


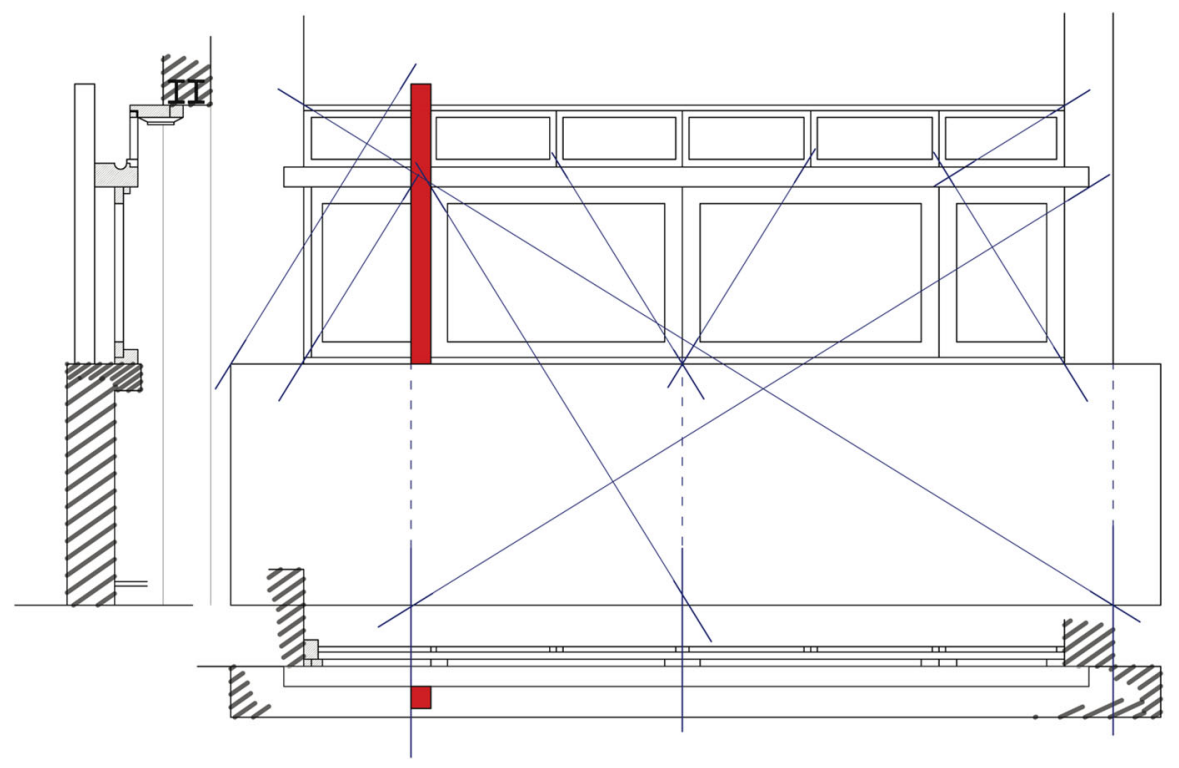

Fig. 10 Detail of the golden lines on the kitchen window, based on Rietveld's original drawing. See how the golden line that meets the lower right corner of the kitchen wall, at ground level, actually lies on the perpendicular wall behind it. Image: the author and Brenda D. Macías

throughout its surface, we found as many golden lines as on the first floor. This fact inevitably leads us to ask ourselves if they were thought of in any way or not, a question that, in the absence of traces of proportions in Rietveld's drawings, is difficult to answer. However, the fact that all of the proportions found are not accurate but instead are just approximate golden line proportions tells us that it was the natural way in which Rietveld drew rectangles. However, what we have learned from the golden lines is how useful they can be in architectural practice to easily draw proportions, such as when one wants to establish the visual reading between picked points of interest for an interior or exterior space, as Rietveld did (consciously or not) in his interior perspective view of the house, whose sight orientation follows a golden line. Again, we do not know how he chose the vantage point; all we know is that the view looks well proportioned.

The form of the house looks to have been built from concrete rather than wood. Would it really have been more expensive to construct the house in concrete (floors and roof) than the actual house in wood? Most articles on the house take for granted that it would have been more expensive in concrete. To clarify this matter, we would have to go back in time, elaborate a comparative budget between the use of concrete vs. wood, and then elucidate if there really were a significant difference in costs. Without reliable data on the costs, the truth about this matter remains uncertain.

By the time the house was under construction, Rietveld was already part of the De Stijl movement, headed by Theo Van Doesburg, making noise in Holland and abroad. Once the house was finished, De Stijl was similar to a large umbrella under 
which Truus's and Rietveld's achievements would be made known to the world. They were not alone in accomplishing great things.

\section{References}

Bois, Yve-Alain. 1987. Mondrian and the Theory of Architecture. Assemblage 4: 103-130.

Brown, Theodore M. 1958. The Work of G. Rietveld Architect (Cambridge MA: MIT Press).

Frietman, Alice. 1998. Women and the Makings of the Modern House (New York: Harry N. Abrams.

García-Salgado, Tomás. 2016. How to Draw Perspective Directly on a 3D Plane. Pp. 673-680 in: Bridges Finland Conference Proceedings, eds. Eve Torrence, Bruce Torrence, Carlo H. Séquin, Douglas McKenna, Kristóf Fenyvesi, and Reza Sarhangi (Tesselations Publishing).

Mulder, Bertus. 2010. Gerrit Thomas Rietveld (Amsterdam: Sun Architecture Publishers and the author). Rietveld, G. 1928. Inzicht. i 10, nos. 17-18: 89-92. Eng. trans. in: Theodore M. Brown, The Work of G. Rietveld Architect (Cambridge MA: MIT Press, 1958), pp. 160-161.

Rietveld archive at the Centraal Museum in Utrecht, The Netherlands. https://www.pinterest.com/ justmyair/rietveld-schröderhuis/

Wright, Frank Lloyd. 1910. The Wasmuth Portfolio. Rpt. Drawings and Plans of Frank Lloyd Wright: The Early Period (1893-1909) (New York: Dover Publications, 1983).

Tomás García-Salgado has a B.A. (1968), M.A. and Ph.D. (1981-1987) in Architecture. He is a tenured researcher in the Faculty of Architecture of UNAM (México City) and holds the distinction of Level III National Researcher (SNI). He has devoted his time to research in perspective geometry since the late 1960s. His main achievement is the theory of Modular Perspective, about which he has published several articles and books. He teaches perspective to bachelor students of architecture at his faculty since 1994 to present. He is also the author of several works of art, architecture and urban design. More information regarding his work is available at: http://perspectivegeometry.com. 